\title{
VARIAÇÃO LINGUÍSTICA E ENSINO NOS DOCUMENTOS OFICIAIS
}

\author{
Claudia Moura da Rocha (UERJ - SELEPROT)
}

Resumo: A variação linguística é um fenômeno intrínseco às línguas. No entanto, existe uma espécie de consenso entre estudiosos e educadores de que ela não é abordada adequadamente no ensino de Língua Portuguesa. Nosso objetivo é refletir sobre a temática, verificando como a abordagem da variação linguística vem sendo implementada no ensino de língua materna. Para tal, neste artigo, realizamos uma análise comparativa de dois documentos oficiais, os PCN e a BNCC, que são responsáveis por nortear a formulação de currículos e de livros didáticos de Língua Portuguesa.

Palavras-chave: Variação linguística; Ensino; PCN; BNCC.

Resúmen: La variación lingüística es un fenómeno intrínseco a los idiomas. Sin embargo, existe una especie de consenso entre académicos y educadores de que no se aborda adecuadamente la variación en la enseñanza del portugués. Nuestro objetivo es reflexionar sobre el tema, verificando cómo se ha implementado el enfoque de la variación lingüística en la enseñanza de la lengua materna. Con este fin, en este artículo, llevamos a cabo un análisis comparativo de dos documentos oficiales, los PCN y la BNCC, que son responsables de guiar la formulación de los planes de estudio y libros de texto en portugués.

Palabras-Ilave: Variación lingüística; Enseñanza; PCN; BNCC.

\section{VARIAÇÃO LINGUÍSTICA E ENSINO: CONSIDERAÇÕES INICIAIS}

Há uma espécie de consenso entre estudiosos e educadores de que o ensino de Língua Portuguesa não aborda a variação linguística como deveria, focando apenas na norma-padrão. Cabe a pergunta: Como então a variação linguística tem sido trabalhada nas aulas de língua materna? Essa pergunta não 
é tão simples de ser respondida, mas podemos refletir sobre ela por meio da análise das diretrizes governamentais sobre o ensino de Língua Portuguesa.

O objetivo deste artigo é justamente pensar sobre esta questão, sem, no entanto, esgotá-la. O que se pretende é averiguar como a abordagem da variação linguística está sendo proposta em documentos oficiais, como os Parâmetros Curriculares Nacionais (PCN) e a Base Nacional Comum Curricular (BNCC). Não é nosso intuito ressaltar a relevância dessa abordagem, uma vez ela que é inquestionável, mas nos propomos a pensar como fazê-la, por meio de sugestões didáticas.

Antes de analisarmos as diretrizes governamentais, por meio dos documentos oficiais, é necessário estabelecer o que se entende por variação linguística. Em seguida, passaremos à análise dos documentos oficiais, para, ao final, tecermos algumas considerações sobre a forma de implementar o estudo da variação linguística no contexto de sala de aula.

\section{O QUE É VARIAÇÃO LINGUÍSTICA?}

A variação é uma característica inerente às línguas. Não há língua que não tenha sofrido alterações ao longo do tempo, assim como não as há que não apresentem diferenças de uso em relação ao lugar ou à situação em que seus usuários se 
encontram. Por essa razão, podemos deduzir que as línguas não são imutáveis, sofrendo, portanto, a ação do tempo e de seus usuários. Elas são dinâmicas. Se assim não fosse, o latim não teria se transformado nas línguas neolatinas (como o italiano, o francês, o espanhol e o português, idioma em que este texto está escrito). Se assim não fosse, nós, no Brasil, não utilizaríamos a palavra camisola com um significado bastante diferente do que a utilizam os portugueses. Não é necessário apelar para distâncias intercontinentais para exemplificar esse tipo de variação, que pode ocorrer dentro do próprio país; melhor dizendo, dentro do mesmo estado. Vejamos, no trecho de uma notícia, um exemplo de variação que ocorre entre duas cidades vizinhas que pertencem ao estado do Rio de Janeiro: a capital, Rio de Janeiro, e Niterói, município da região metropolitana do Rio de Janeiro.

Italiano: uma exclusividade dos niteroienses Quer deixá-los irados? É só chamar a delícia de... joelho, à moda carioca

Leonardo Sodré

23/11/2015 - 07:00

NITERÓl - O italiano, salgado amado pelos niteroienses e o mais pedido nas cantinas de colégios e lanchonetes, é também sinônimo de bairrismo. Chamado pelos cariocas de joelho, por aqui, além de outro nome, ele ganhou versões mais elaboradas, o que faz moradores acreditarem - de verdade! - que, apesar de semelhante aparência, 
trata-se de outro salgado: uma exclusividade nossa! (O Globo, 23/11/2015). ${ }^{1}$

Outras variações, no uso da língua, ocorrem de acordo com a situação em que ela estiver sendo utilizada. Um falante não se expressa da mesma maneira em duas ocasiões distintas: com os amigos, ele não fala de forma semelhante à como falaria em uma entrevista de emprego, utilizando-se de registros diferentes.

Mateus e Cardeira (2007, p.80) resumem o que seria variação: "fenômeno presente em todas as línguas naturais, encaradas como sistemas dinâmicos, e que se traduz pela diversidade do seu uso pelos falantes".

E por que as línguas variam? Segundo Terra (2018, p.72), como a língua é uma instituição social, espelha a sociedade; como a sociedade é heterogênea, sendo constituída por diversos grupos sociais, cujos integrantes pertencem às mais diversas classes sociais e são oriundos de lugares diferentes, a língua também o é. Uma língua não é uma entidade indivisível, uniforme, homogênea, porque ela é um conjunto de variedades. Ela se caracteriza pela unidade na diversidade (CUNHA, 1994; HOUAISS, 1992; MATEUS; CARDEIRA, 2007). A unidade se explica porque a língua é uma marca identitária,

1 In https://oglobo.globo.com/rio/bairros/italiano-uma-exclusividade-dosniteroienses-18098939 Acesso em 1.Jul.2020. 
reunindo traços linguísticos que nos permitem dizer que falamos a mesma língua; a diversidade se impõe porque não falamos da mesma maneira, há formas diferentes de os usuários empregarem a mesma língua.

As formas de variação linguística interessam, em especial, à Sociolinguística, à Linguística Histórica e à Dialetologia. Conceituados estudiosos propuseram classificações para a variação linguística, que, apesar de diferentes, apresentam muitos pontos em comum, como veremos a seguir.

Dino Preti, em Sociolinguística: os níveis de fala (1994, p.24-25), obra de referência nos estudos sociolinguísticos, divide as variedades em dois grandes grupos, em que o primeiro (das variedades geográficas ou diatópicas) engloba o segundo (das variedades socioculturais ou diastráticas). Segundo ele, as variedades geográficas "são aquelas que ocorrem num plano horizontal da língua, na concorrência das comunidades linguísticas, sendo responsáveis pelos chamados regionalismos, provenientes de dialetos ou falares locais" (PRETI, 1994, p.24). Elas estabeleceriam uma oposição entre a linguagem urbana e a rural. Aquela, mais próxima da linguagem comum decorrente da ação de fatores culturais, como a escola, os meios de comunicação de massa, a literatura. Esta, "mais conservadora e isolada, 
extinguindo-se gradualmente com a chegada da civilização" (PRETI, 1994, p.25). O estudioso ressalta que, dentro dos limites da linguagem urbana e da rural, podem ocorrer outras variações ocasionadas pelas características do falante e do grupo a que ele pertence ou pelas circunstâncias que envolvem o ato de fala (a situação).

Tais variações, que fariam parte do primeiro grupo (das variedades geográficas), são chamadas de variedades socioculturais ou diastráticas. Essas variedades "ocorrem num plano vertical, isto é, dentro da linguagem de uma comunidade específica (urbana ou rural)" (PRETI, 1994, p.25), sendo influenciadas por fatores relacionados ao falante ou ao grupo a que pertence (como idade, sexo, raça ou cultura, profissão, posição social, grau de escolaridade, local em que reside na comunidade), à situação (como o ambiente, o tema, o estado emocional do falante, o grau de intimidade entre os falantes) ou a ambos. Ainda segundo o autor, é possível identificar, em qualquer área geográfica (mais provavelmente na linguagem urbana), os dialetos sociais culto e popular. Sobre esses dialetos, destaca a questão do prestígio: maior do dialeto social culto (empregado em situações de maior formalidade) e menor do popular (empregado em situações coloquiais de menor formalidade) 
(PRETI, 1994, p.26-30). Em relação aos fatores situacionais, nova distinção pode ser proposta, a de níveis de fala: "Dá-se o nome de níveis de fala (ou níveis de linguagem) ou registros às variações determinadas pelo uso da língua pelo falante, em situações diferentes" (PRETI, 1994, p.38). Os níveis podem ser formal (utilizado em situações de formalidade) ou coloquial (empregado em situações familiares, diálogos informais em que ocorre maior intimidade entre os falantes) (PRETI, 1994, p.38).

Mateus e Cardeira (2007, p.80), por sua vez, apresentam uma classificação mais sucinta, apontando os seguintes tipos de variação: variação diacrônica (as línguas variam no tempo), diatópica (as línguas variam no espaço geográfico), diastrática (as línguas variam na sociedade) e diafásica (as línguas variam segundo as modalidades expressivas).

Ilari e Basso (2006, p.151-194) também fazem referência às variações diacrônica, diatópica, diastrática, além de propor a designação diamésica, "que se refere aos vários veículos ou meios de expressão que a língua utiliza", compreendendo as diferenças existentes entre a língua falada e a escrita e o gênero discursivo como fator de variação. Os autores ainda salientam que essas variações coexistem nas produções verbais, não ocorrendo isoladamente. 
Ilari e Basso, assim como Terra (2018, p.73-74), mencionam uma espécie de variação relacionada à variedade escrita e à falada. É conveniente estabelecer mais detalhadamente as diferenças entre essas duas modalidades da língua. Não há dúvidas de que fala e escrita são diferentes; a fala precedeu historicamente a escrita, mas o emprego do termo modalidade nos permite perceber que uma não pode ser considerada como superior à outra. São apenas formas diferentes de utilizar a língua, ou seja, modalidades distintas da mesma língua.

Fávero, Andrade e Aquino (2002, p.74) apontam as principais características de cada uma das modalidades em relação às suas condições de produção. $\mathrm{Na}$ fala, a interação ocorre face a face, enquanto, na escrita, a interação se dá a distância (espaço-temporal). O planejamento da fala acontece de forma simultânea (ou quase simultânea) à sua produção, diferentemente da escrita, em que o planejamento é anterior à sua produção. Se a fala é uma criação coletiva dos interlocutores, por sua vez a escrita é uma criação individual. A fala é marcada pela impossibilidade de apagamento do que foi dito, mas, na escrita, há a possibilidade de revisão. $\mathrm{Na}$ fala, não há condições de consultar outros textos, o que é possível na escrita. Quanto à reformulação textual, 
na fala, pode ser feita por qualquer um dos interlocutores; no texto escrito, apenas pelo escritor. Quanto à reação do interlocutor, na fala, é imediata; na escrita, isso não ocorre. A partir dessas reações, o falante pode processar seu texto, redirecionando-o; na escrita, esse processamento ocorre a partir das reações que o autor imagina que o leitor pode vir a ter. Na fala, o processo de criação do texto é evidente; nos textos, o seu processo de criação não é explícito, estando disponível apenas o resultado desse processo.

É preciso destacar que os textos orais contam com recursos de que os escritos não dispõem e vice-versa: naqueles, a expressão fisionômica, os gestos, a entoação; nestes, os sinais de pontuação.

Não é possível tratar de variação linguística sem abordar o conceito de norma. A palavra norma não só remete à ideia de normal, habitual, como também à de modelo, um padrão a ser seguido. Do primeiro sentido, vem a concepção de norma como o que é normal entre os usuários de uma língua, de como eles habitualmente se expressam. Considerando-se a heterogeneidade linguística, uma língua seria um conjunto de normas correspondentes às variedades linguísticas existentes. Do segundo sentido, norma seria um padrão linguístico a ser imitado, seguido, o que costuma ser 
denominado norma-padrão. A norma-padrão é um construto idealizado, com um caráter normativo, prescritivo (FARACO; ZILLES, 2017, p.12-26; MATEUS; CARDEIRA, 2007, p.23-27).

A norma-padrão costuma ser confundida com a própria língua, o que é um equívoco, pois, ela "é uma realidade construída, idealizada, um modelo de língua a ser seguido em determinados contextos", ou seja, é um padrão linguístico que permitiria uma comunicação bem-sucedida entre todos os falantes, conferindo prestígio a quem a domina. É costumeiramente associada à correção linguística, o que contribui para o julgamento de que as outras variedades são incorretas, estigmatizando-as (FARACO; ZILLES, 2017, p.12, 29, 51).

Outro equívoco recorrente é associar a norma-padrão à norma culta. A norma culta é a norma empregada pelos falantes com maior nível de escolarização e com maior prestígio social, o que acaba conferindo a essa norma uma posição privilegiada em relação às outras. A norma culta não deve, portanto, ser confundida com a norma-padrão. Há ainda que se ressaltar a inadequação do termo culta, uma vez que pode sugerir que apenas seus falantes são cultos, ou seja, têm cultura, quando se deve considerar que o termo faz menção apenas à cultura escrita (FARACO; ZILLES, 2017, p.18-20; MATEUS; CARDEIRA, 2007, p.26-27). 
Por norma culta designa-se tecnicamente o conjunto das características linguísticas do grupo de falantes que se consideram cultos (ou seja, a "norma normal" desse grupo social específico). Na sociedade brasileira, esse grupo é tipicamente urbano, tem elevado nível de escolaridade e faz amplo uso dos bens da cultura escrita. A chamada norma culta é uma "norma normal", porque é uma das tantas normas presentes na dinâmica corrente, viva, do funcionamento social da língua. (FARACO; ZILLES, 2017, p.19)

\section{A VARIAÇÃO LINGUÍSTICA NOS DOCUMENTOS OFICIAIS: PCN E BNCC}

Como os documentos oficiais oferecem aos sistemas de ensino e aos professores as diretrizes para o ensino de Língua Portuguesa, além de balizarem a organização dos livros didáticos, material didático ainda largamente utilizado no país, muito em virtude de sua distribuição pelo Governo Federal, sua análise nos permite verificar como se deve dar ou não a abordagem da variação no ensino, permitindo-nos ainda refletir sobre a concepção, bastante consensual, de que a variação não é tratada como deveria.

Comecemos pelos Parâmetros Curriculares Nacionais

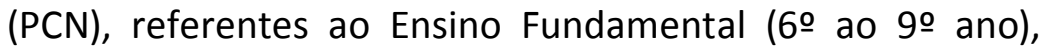
publicados em 1998 e formulados com base nas contribuições dos estudos linguísticos, como as da Linguística Textual. Segundo o documento, seu objetivo era, apesar do respeito 
às diversidades regionais, culturais, políticas existentes, ser uma referência nacional comum ao processo educativo em todas as regiões do país (PCN, 1998, p.5). O documento propõe uma nova abordagem didática, tomando o texto como o centro do ensino de Língua Portuguesa, evitando a abordagem descontextualizada de conteúdos linguísticos. Em relação à variação linguística, o documento é bastante explícito sobre sua relevância e sobre a forma como deve ser executada a sua abordagem, levando os alunos a reconhecerem todas as variedades linguísticas como válidas, além de evitarem o preconceito linguístico.

O documento menciona propostas de reformulação do ensino anteriores (décadas de 1960 e 1970), em que fica evidente como a variação linguística era tratada (nesse período, pode-se afirmar que a norma culta se confundia com a norma-padrão):

Na década de 60 e início de 70, as propostas de reformulação do ensino de Língua Portuguesa indicavam, fundamentalmente, mudanças no modo de ensinar, pouco considerando os conteúdos de ensino. Acreditava-se que valorizar a criatividade seria condição suficiente para desenvolver a eficiência da comunicação e expressão do aluno. Além disso, tais propostas se restringiam aos setores médios da sociedade, sem se dar conta das consequências profundas que a incorporação dos filhos das camadas pobres 
implicava. O ensino de Língua Portuguesa orientado pela perspectiva gramatical ainda parecia adequado, dado que os alunos que frequentavam a escola falavam uma variedade linguística bastante próxima da chamada variedade padrão e traziam representações de mundo e de língua semelhantes às que ofereciam livros e textos didáticos. (PCN, 1998, p.17)

Somente na década de 1980, os estudos sobre a variação linguística seriam incorporados a essas reformulações, identificando-se a crítica ao ensino excessivo da gramática normativa. É digna de destaque também a menção à ressignificação do conceito de erro (veremos que houve, em seu lugar, a adoção do conceito de adequação) e ao estigma social de variedades linguísticas empregadas pelos alunos:

A nova crítica do ensino de Língua Portuguesa, no entanto, só se estabeleceria mais consistentemente no início dos anos 80, quando as pesquisas produzidas por uma linguística independente da tradição normativa e filológica e os estudos desenvolvidos em variação linguística e psicolinguística, entre outras, possibilitaram avanços nas áreas de educação e psicologia da aprendizagem, principalmente no que se refere à aquisição da escrita.

[...]

Entre as críticas mais frequentes que se faziam ao ensino tradicional destacavam-se:

[...]

- excessiva valorização da gramática 
normativa e a insistência nas regras de exceção, com o consequente preconceito contra as formas de oralidade e as variedades não padrão;

[...]

- a apresentação de uma teoria gramatical inconsistente - uma espécie de gramática tradicional mitigada e facilitada.

É neste período que ganha espaço um conjunto de teses que passam a ser incorporadas e admitidas, pelo menos em teoria, por instâncias públicas oficiais. A divulgação dessas teses desencadeou um esforço de revisão das práticas de ensino da língua, na direção de orientá-las para a ressignificação da noção de erro, a admissão das variedades linguísticas próprias dos alunos, muitas delas marcadas pelo estigma social, e para a valorização das hipóteses linguísticas elaboradas pelos alunos no processo de reflexão sobre a linguagem e para o trabalho com textos reais, ao invés de textos especialmente construídos para o aprendizado da escrita. (PCN, 1998, p.17-18)

Norteia o documento, a concepção de língua como um conjunto de variedades (PCN, 1998, p.81-82), não sendo coerente pensar na existência de uma língua homogênea que se confundiria com a norma-padrão:

A variação é constitutiva das línguas humanas, ocorrendo em todos os níveis. Ela sempre existiu e sempre existirá, independentemente de qualquer ação normativa. Assim, quando se fala em 
"Língua Portuguesa" está se falando de uma unidade que se constitui de muitas variedades. Embora no Brasil haja relativa unidade linguística e apenas uma língua nacional, notam-se diferenças de pronúncia, de emprego de palavras, de morfologia e de construções sintáticas, as quais não somente identificam os falantes de comunidades linguísticas em diferentes regiões, como ainda se multiplicam em uma mesma comunidade de fala. Não existem, portanto, variedades fixas: em um mesmo espaço social convivem mescladas diferentes variedades linguísticas, geralmente associadas a diferentes valores sociais. Mais ainda, em uma sociedade como a brasileira, marcada por intensa movimentação de pessoas e intercâmbio cultural constante, o que se identifica é um intenso fenômeno de mescla linguística, isto é, em um mesmo espaço social convivem mescladas diferentes variedades linguísticas, geralmente associadas a diferentes valores sociais.

O uso de uma ou outra forma de expressão depende, sobretudo, de fatores geográficos, socioeconômicos, de faixa etária, de gênero (sexo), da relação estabelecida entre os falantes e do contexto de fala. A imagem de uma língua única, mais próxima da modalidade escrita da linguagem, subjacente às prescrições normativas da gramática escolar, dos manuais e mesmo dos programas de difusão da mídia sobre "o que se deve e o que não se deve falar e escrever", não se sustenta na análise empírica dos usos da língua. (PCN, 1998, p.29) 
Ao longo do documento, identifica-se uma preocupação constante com a adequação linguística. A abordagem correta seria tratar da adequação das formas às situações e não as considerar como um erro. Ao tratar da adequação, é mencionado que a língua deve ser considerada um fenômeno heterogêneo (PCN, 1998, p.18-19, 23, 51, 82):

No ensino-aprendizagem de diferentes padrões de fala e escrita, o que se almeja não é levar os alunos a falar certo, mas permitir-lhes a escolha da forma de fala a utilizar, considerando as características e condições do contexto de produção, ou seja, é saber adequar os recursos expressivos, a variedade de língua e o estilo às diferentes situações comunicativas: saber coordenar satisfatoriamente o que fala ou escreve e como fazê-lo; saber que modo de expressão é pertinente em função de sua intenção enunciativa - dado o contexto e os interlocutores a quem o texto se dirige. A questão não é de erro, mas de adequação às circunstâncias de uso, de utilização adequada da linguagem. (PCN, 1998, p.31)

Além disso, identificam-se, ao longo do texto, várias menções à importância de levar o aluno a reconhecer e a evitar o preconceito linguístico (do qual ele mesmo pode ter sido vítima), valorizando a diversidade linguística - inclusive a sua própria variedade ("todas as variedades linguísticas são legítimas"). Cabe à escola combater a discriminação linguística (PCN, 1998, p.31, 51-52, 82): 
A Língua Portuguesa é uma unidade composta de muitas variedades. O aluno, ao entrar na escola, já sabe pelo menos uma dessas variedades - aquela que aprendeu pelo fato de estar inserido em uma comunidade de falantes. Certamente, ele é capaz de perceber que as formas da língua apresentam variação e que determinadas expressões ou modos de dizer podem ser apropriados para certas circunstâncias, mas não para outras. Sabe, por exemplo, que existem formas mais ou menos delicadas de se dirigir a alguém, falas mais cuidadas e refletidas, falas cerimoniosas. Pode ser que saiba, inclusive, que certos falares são discriminados e, eventualmente, até ter vivido essa experiência. (PCN, 1998, p.81-82)

O documento reconhece as diferenças entre as modalidades oral e escrita, cabendo "à escola ensinar o aluno a utilizar a linguagem oral no planejamento e realização de apresentações públicas: realização de entrevistas, debates, seminários, apresentações teatrais etc.", pois dificilmente acontecerá a aprendizagem de procedimentos apropriados de fala e de escuta (em contextos públicos) se isso não for uma iniciativa da escola (PCN, 1998, p.25, 51):

Em primeiro lugar, está o fato de que ninguém escreve como fala, ainda que em certas circunstâncias se possa falar um texto previamente escrito (é o que ocorre, por exemplo, no caso de uma conferência, de um discurso formal, dos telejornais) ou mesmo falar tendo por referência padrões 
próprios da escrita, como em uma exposição de um tema para auditório desconhecido, em uma entrevista, em uma solicitação de serviço junto a pessoas estranhas. Há casos ainda em que a fala ganha contornos ritualizados, como nas cerimônias religiosas, comunicados formais, casamentos, velórios etc. No dia-a-dia, contudo, a organização da fala, incluindo a escolha de palavras e a organização sintática do discurso, segue padrões significativamente diferentes daqueles que se usam na produção de textos escritos. (PCN, 1998, p.30)

Segundo os PCN, o papel da escola é permitir que o aluno desenvolva sua competência discursiva, ou seja, que o aluno seja capaz de empregar "a língua de modo variado, para produzir efeitos de sentido e adequar o texto a diferentes situações de interlocução oral e escrita". Para tal, a escola deve organizar atividades de ensino-aprendizagem da língua e da linguagem (PCN, 1998, p.23). A importância de se estudar a língua escrita e a língua padrão (que podemos considerar como um sinônimo de norma-padrão) é evidenciada, uma vez que o aluno não vai à escola para aprender aquilo que já sabe:

Tomar a língua escrita e o que se tem chamado de língua padrão como objetos privilegiados de ensino-aprendizagem na escola se justifica, na medida em que não faz sentido propor aos alunos que aprendam o que já sabem. Afinal, a aula deve ser o 
espaço privilegiado de desenvolvimento de capacidade intelectual e linguística dos alunos, oferecendo-Ihes condições de desenvolvimento de sua competência discursiva. Isso significa aprender a manipular textos escritos variados e adequar o registro oral às situações interlocutivas, o que, em certas circunstâncias, implica usar padrões mais próximos da escrita. (PCN, 1998, p.30)

O documento aponta a variação linguística (modalidades, variedades, registros) como um dos aspectos linguísticos que podem ampliar a competência discursiva do sujeito, o que demonstra o destaque a ela dado (PCN, 1998, p.36).

O documento lista, de forma exaustiva e detalhada, os conteúdos a serem desenvolvidos nas práticas de escuta de textos orais, de leitura de textos escritos e produção de textos orais e escritos. No tocante à variação, podem ser destacadas as seguintes menções, na prática de análise linguística, à observação da língua em uso a fim de lidar com a "variação intrínseca ao processo linguístico", no que se refere aosfatores geográficos, históricos, sociológicos, técnicos; às diferenças entre os padrões da linguagem oral e os da linguagem escrita; à escolha do registro em função da situação interlocutiva; aos diferentes componentes do sistema linguístico em que a variação se manifesta: na fonética (diferentes pronúncias), no léxico (diferentes empregos de palavras), na morfologia 
(variantes e reduções no sistema flexional e derivacional), na sintaxe (estruturação das sentenças e concordância); à comparação dos fenômenos linguísticos observados na fala e na escrita nas diferentes variedades (PCN, 1998, p.59-61); à ampliação do repertório lexical pelo ensino-aprendizagem de novas palavras, de modo a permitir a escolha mais adequada em relação à modalidade falada ou escrita ou ao nível de formalidade e finalidade social do texto (PCN, 1998, p.62-63). Na escuta de textos orais, identificação das formas particulares dos gêneros literários do oral que se distinguem do falar cotidiano (PCN, 1998, p.55). No tocante à produção de textos orais, menção ao planejamento prévio da fala (PCN, 1998, p.58).

Entre os valores e as atitudes subjacentes às práticas de linguagem, a valorização das variedades linguísticas regionais se sobressai, sendo a primeira a ser apontada, além de haver o reconhecimento de que o domínio dos usos sociais das modalidades oral e escrita permite uma inserção mais efetiva do aluno no mundo do trabalho, além de lhe garantir participação política e cidadã (PCN, 1998, p.64-65).

O documento ainda apresenta propostas de atividades para explorar a variação linguística e a menciona no tocante a critérios para a avaliação da aprendizagem (PCN, 1998, p.82-83, 96-97). 
Ainda são citados os mitos dos quais a escola deveria se livrar, para ensinar a escrita e a língua padrão: o de que há uma forma "correta" de falar; o de que a fala de uma região é melhor do que a das outras; o de que a fala "correta" é a que se aproxima da língua escrita; o de que o brasileiro fala mal o português; o de que o português é uma língua difícil; o de que é preciso "consertar" a fala do aluno para evitar que ele escreva errado (PCN, 1998, p.31). A seguir, é ressaltado um aspecto muito importante, o de que o aprendizado de outras modalidades de fala e de padrões de escrita não ocorreria por substituição, mas sim pela extensão da competência linguística:

Essas crenças insustentáveis produziram uma prática de mutilação cultural que, além de desvalorizar a fala que identifica o aluno a sua comunidade, como se esta fosse formada de incapazes, denota desconhecimento de que a escrita de uma língua não corresponde a nenhuma de suas variedades, por mais prestígio que uma delas possa ter. Ainda se ignora um princípio elementar relativo ao desenvolvimento da linguagem: o domínio de outras modalidades de fala e dos padrões de escrita (e mesmo de outras línguas) não se faz por substituição, mas por extensão da competência linguística e pela construção ativa de subsistemas gramaticais sobre o sistema já adquirido. (PCN, 1998, p.31)

Entre os objetivos gerais de Língua Portuguesa para o Ensino Fundamental, destacamos alguns dos apontados pelo 
documento por serem relativos à abordagem da variação linguística, o que comprova a preocupação dos PCN com o tema:

Para isso, a escola deverá organizar um conjunto de atividades que, progressivamente, possibilite ao aluno:

[...]

- analisar criticamente os diferentes discursos, inclusive o próprio, desenvolvendo a capacidade de avaliação dos textos:

[...]

- identificando e repensando juízos de valor tanto socioideológicos (preconceituosos ou não) quanto histórico-culturais (inclusive estéticos) associados à linguagem e à língua;

- conhecer e valorizar as diferentes variedades do Português, procurando combater o preconceito linguístico;

- reconhecer e valorizar a linguagem de seu grupo social como instrumento adequado e eficiente na comunicação cotidiana, na elaboração artística e mesmo nas interações com pessoas de outros grupos sociais que se expressem por meio de outras variedades. (PCN, 1998, p.32-33)

Como se percebe, no final da década de 1990, os PCN já apontavam a abordagem da variação linguística como um objetivo a ser alcançado, mas talvez esta questão ainda não esteja totalmente resolvida, uma vez que documentos recentes, como a BNCC (Base Nacional Comum Curricular), 
ainda tratam a implementação da variação linguística como uma meta a ser alcançada com premência.

Em 2015, quase duas décadas após a publicação dos PCN, novo documento oficial sobre o ensino começa a ser elaborado, contando com a mobilização de professores de todo o país a fim de discutir o documento preliminar. Ao longo do ano de 2016, uma nova versão do documento foi sendo debatida. No mesmo ano, começa a ser redigida, de forma colaborativa, sua terceira versão. Em dezembro de 2017, a BNCC é homologada. Somente em dezembro de 2018, a seção da BNCC correspondente ao Ensino Médio foi homologada. Analisaremos, neste artigo, a seção dedicada ao Ensino Fundamental (6ㅇ ao 9a ano).

Destacamos que esse documento faz referência aos PCN, permitindo entrever que não se distanciará de suas orientações, ao contrário, intentará atualizá-las, seguindo inclusive a perspectiva enunciativo-discursiva de linguagem:

O componente Língua Portuguesa da BNCC dialoga com documentos e orientações curriculares produzidos nas últimas décadas, buscando atualizá-los em relação às pesquisas recentes da área e às transformações das práticas de linguagem ocorridas neste século, devidas em grande parte ao desenvolvimento das tecnologias digitais da informação e comunicação (TDIC). Assume-se aqui a perspectiva enunciativo- 
discursiva de linguagem, já assumida em outros documentos, como os Parâmetros Curriculares Nacionais (PCN), para os quais a linguagem é "uma forma de ação interindividual orientada para uma finalidade específica; um processo de interlocução que se realiza nas práticas sociais existentes numa sociedade, nos distintos momentos de sua história" (BRASIL, 1998, p.20; 2018, p.67)

O documento também se baseia na concepção de língua como um conjunto de variedades, apresentando a língua uma natureza heterogênea e dinâmica, além de mencionar a existência de variedades prestigiadas e outras estigmatizadas, o que remete ao preconceito linguístico, que deve ser debatido. Percebe-se, assim como nos PCN, uma postura de valorização da diversidade linguística e repúdio à estigmatização de qualquer variedade linguística (BRASIL, 2018, p.83, 87):

Cabem também reflexões sobre os fenômenos da mudança linguística e da variação linguística, inerentes a qualquer sistema linguístico, e que podem ser observados em quaisquer níveis de análise. Em especial, as variedades linguísticas devem ser objeto de reflexão e o valor social atribuído às variedades de prestígio e às variedades estigmatizadas, que está relacionado a preconceitos sociais, deve ser tematizado. (BRASIL, 2018, p.81)

O documento, ao enfocar a diversidade linguística, amplia o enfoque anteriormente dado pelos PCN, ao tratar, por 
exemplo, das línguas indígenas, das afro-brasileiras e da Língua Brasileira de Sinais:

Ainda em relação à diversidade cultural, cabe dizer que se estima que mais de 250 línguas são faladas no país - indígenas, de imigração, de sinais, crioulas e afrobrasileiras, além do português e de suas variedades. Esse patrimônio cultural e linguístico é desconhecido por grande parte da população brasileira.

No Brasil com a Lei no 10.436, de 24 de abril de 2002, oficializou-se também a Língua Brasileira de Sinais (Libras), tornando possível, em âmbito nacional, realizar discussões relacionadas à necessidade do respeito às particularidades linguísticas da comunidade surda e do uso dessa língua nos ambientes escolares.

Assim, é relevante no espaço escolar conhecer e valorizar as realidades nacionais e internacionais da diversidade linguística e analisar diferentes situações e atitudes humanas implicadas nos usos linguísticos, como o preconceito linguístico. Por outro lado, existem muitas línguas ameaçadas de extinção no país e no mundo, o que nos chama a atenção para a correlação entre repertórios culturais e linguísticos, pois o desaparecimento de uma língua impacta significativamente a cultura.

(BRASIL, 2018, p.70)

Sobressai, ao longo do documento, a constante menção à norma-padrão, o que indicia o papel da escola em garantir sua aquisição e sua relevância na formação de usuários da 
língua mais proficientes. No entanto, o ensino da normapadrão não deve ser tomado como um fim em si mesmo, ao contrário, deve proporcionar a prática de reflexão linguística (BRASIL, 2018, p.80, 139):

Os conhecimentos sobre os gêneros, sobre os textos, sobre a língua, sobre a normapadrão, sobre as diferentes linguagens (semioses) devem ser mobilizados em favor do desenvolvimento das capacidades de leitura, produção e tratamento das linguagens, que, por sua vez, devem estar a serviço da ampliação das possibilidades de participação em práticas de diferentes esferas/campos de atividades humanas. (BRASIL, 2018, p.67)

Cabe ressaltar, reiterando o movimento metodológico de documentos curriculares anteriores, que estudos de natureza teórica e metalinguística - sobre a língua, sobre a literatura, sobre a norma-padrão e outras variedades da língua - não devem nesse nível de ensino ser tomados como um fim em si mesmo, devendo estar envolvidos em práticas de reflexão que permitam aos estudantes ampliarem suas capacidades de uso da língua/linguagens (em leitura e em produção) em práticas situadas de linguagem. (BRASIL, 2018, p.71)

A norma-padrão é mencionada em seis habilidades a serem desenvolvidas no ensino de Língua Portuguesa: EF69LP55, EF69LP56, EF89LP09, EF09LP04, EF09LP07, EF09LP10. É indicado que o aluno reconheça o conceito de norma-padrão, 
faça o uso consciente e reflexivo de suas regras e normas nas situações de fala e escrita em que deve ser usada, além de comparar o uso da regência (verbal e nominal) e as regras de colocação pronominal que obedecem à norma-padrão com o seu uso no português brasileiro coloquial (BRASIL, 2018, p.161, 179, 187, 189, 191).

Identificamos uma única menção à norma culta, na seção dedicada às práticas de linguagem (campo jornalísticomidiático/produção de textos), objetos de conhecimento (revisão/edição de texto informativo e opinativo), na seguinte habilidade:

(EF69LP08) Revisar/editar o texto produzido - notícia, reportagem, resenha, artigo de opinião, dentre outros -, tendo em vista sua adequação ao contexto de produção, a mídia em questão, características do gênero, aspectos relativos à textualidade, a relação entre as diferentes semioses, a formatação e uso adequado das ferramentas de edição (de texto, foto, áudio e vídeo, dependendo do caso) e adequação à norma culta. (BRASIL, 2018, p.143)

Parece-nos um mero lapso, uma vez que o documento foi escrito colaborativamente, passando porvárias reformulações até chegar à versão final, e não necessariamente uma contradição, pois, como se pode perceber, a expressão norma culta pode muito bem ser substituída, neste trecho, por norma-padrão. 
A BNCC menciona a necessidade de desenvolver estratégias de planejamento, revisão, edição, reescrita/ redesign e avaliação de textos, considerando sua adequação à modalidade da língua (oral ou escrita), à variedade linguística e, inclusive, à norma-padrão (BRASIL, 2018, p.78). A questão da adequação também é indicada no seguinte trecho, em que há menção à escolha de variedade linguística:

No caso de textos orais, essa análise envolverá também os elementos próprios da fala - como ritmo, altura, intensidade, clareza de articulação, variedade linguística adotada, estilização etc. - assim como os elementos paralinguísticos e cinésicos postura, expressão facial, gestualidade etc. No que tange ao estilo, serão levadas em conta as escolhas de léxico e de variedade linguística ou estilização e alguns mecanismos sintáticos e morfológicos, de acordo com a situação de produção, a forma e o estilo de gênero. (BRASIL, 2018, p.80)

As características que distinguem as modalidades oral e escrita também devem ser objeto de ensino, segundo a BNCC:

Relação entre fala e escrita

- Estabelecer relação entre fala e escrita, levando-se em conta o modo como as duas modalidades se articulam em diferentes gêneros e práticas de linguagem (como jornal de TV, programa de rádio, apresentação de seminário, mensagem instantânea 
etc.), as semelhanças e as diferenças entre modos de falar e de registrar o escrito e os aspectos sociodiscursivos, composicionais e linguísticos de cada modalidade sempre relacionados com os gêneros em questão. (BRASIL, 2018, p.80)

A variação linguística, além de ser tomada como um objeto de conhecimento pela BNCC $(2018$, p.160, 191), é citada explicitamente em pelo menos cinco das habilidades que devem ser estimuladas no ensino de Língua Portuguesa: EF69LP12, EF69LP47, EF69LP50, EF69LP52, EF69LP55. A primeira habilidade é associada à produção de texto oral; a segunda, à leitura de texto narrativo ficcional; a terceira, à produção de texto dramático; a quarta, à produção de textos orais dramáticos (sua representação); na quinta, à análise linguística da variação linguística ("Reconhecer as variedades da língua falada, o conceito de norma-padrão e o de preconceito linguístico") (BRASIL, 2018, p.145, 159, 161).

\section{ABORDAGEM DIDÁTICA DA VARIAÇÃO LINGUÍSTICA}

Após essa breve análise de dois documentos que traçam as diretrizes do ensino de Língua Portuguesa, percebe-se a patente relevância de se incluir a abordagem da variação linguística no ensino por, no mínimo, quatro razões.

A primeira razão seria a necessidade de dotar os alunos de mais recursos, mais instrumentos para se comunicarem de 
maneira proficiente. Como se sabe, ao abordar a diversidade linguística existente, 0 aluno se torna mais consciente de que a língua não é homogênea, sendo um conjunto de variedades, e também de que não existem variedades certas ou erradas. Dessa forma, perceberá a necessidade de se adequar às situações. Não é o caso de trocar a sua variedade por outra, mas de saber transitar com mais desenvoltura entre as variedades. Como se viu, nos PCN, não é um caso de substituir, mas de ampliar sua competência linguística.

Duas metáforas, propostas por estudiosos de peso da língua portuguesa, são bastante conhecidas dos professores de língua, resumindo a necessidade de levar o aluno a desenvolver a habilidade de adaptar-se linguisticamente às situações. Bechara (2006, p.13-14) salienta que o falante deve ser um poliglota em sua própria língua, enquanto Faraco e Zilles (2017, p.37-38) propõem que ele seja um camaleão linguístico.

O que essas duas metáforas nos permitem perceber é que reconhecer a variação e saber lidar com ela é imprescindível ao falante para se tornar um usuário eficiente de sua própria língua, sabendo empregá-la com sucesso. Elas reforçam o conceito de adequação linguística, sendo fortes indícios da relevância de se incorporar a variação ao ensino de 
língua portuguesa, o que vem sendo ressaltado em muitos estudos acadêmicos. Assim como saber outras línguas é um requisito para a escolha de um bom profissional, identificar as variedades da sua própria língua, sabendo transitar entre elas, o que inclui dominar a norma-padrão e saber adequarse às situações, também é uma qualidade desejável em um profissional.

A segunda razão seria a de evitar o preconceito linguístico, uma vez que, ao reconhecer que a língua não é homogênea nem estática, ao contrário, é heterogênea e dinâmica, o aluno perceberia que não deve fazer juízos de valor sobre as variedades, respeitando-as, sendo mais tolerante com os outros falantes, incluindo seus colegas e parentes. Reconhecer a diversidade linguística é meio caminho para respeitar a diversidade cultural. Esse respeito é fundamental, principalmente em um período marcado por tanta intolerância.

A terceira razão seria a valorização de sua própria identidade, porque a língua é um fator identitário. Uma das razões por que nos consideramos uma nação é o fato de falarmos a mesma língua, mesmo que não a falemos da mesma maneira. É a unidade na diversidade, como vimos. Reconhecendo a diversidade, mas também a unidade de uma 
língua como o português, o aluno reconhece o valor de sua língua e também de sua forma de se expressar. $\mathrm{O}$ aluno não terá vergonha da variedade linguística que ele e seu grupo social utilizam. Como um reflexo desse desconhecimento sobre a variação linguística, muitos alunos acreditam que não sabem português, quando na verdade não sabem uma de suas variedades, a norma-padrão.

A quarta razão seria identificar as diferenças entre as modalidades oral e escrita. Levar os alunos a identificarem tais diferenças é necessário, uma vez que se pode constatar com relativa frequência a influência da modalidade oral na escrita. É comum verificar, ao analisar suas produções escritas, que eles escrevem como falam, identificando-se marcas de oralidade, como os marcadores conversacionais (como bem, bom, iniciando os textos); que não utilizam a pontuação ou escrevem períodos muito longos, separados unicamente por vírgulas, reproduzindo o jeito de falar.

Estas seriam algumas das principais razões (não as únicas) para abordamos a variação linguística em sala de aula. Passemos a algumas sugestões de como fazê-lo.

Para tratar das variedades históricas ou diacrônicas, o professor pode trabalhar, por exemplo, textos que tratem de mudanças que ocorreram no léxico da língua portuguesa 
ao longo do tempo. A obra Bisa Bia, Bisa Bel, de Ana Maria Machado (2007), apresenta um capítulo ("Conversas de antigamente"), em que as personagens, uma bisavó e sua bisneta, conversam sobre os objetos do passado, sendo possível abordar a noção de arcaísmos, palavras que caíram em desuso, e entre eles a predominância de certos estrangeirismos, o que denota o prestígio da língua francesa na época de sua bisavó (atualmente a preferência seria pelas palavras de origem inglesa), como etagére, bibelô, urinol, criado-mudo, bonbonnière, opalina, plafonnier. A crônica "Antigamente", de Carlos Drummond de Andrade (SANTOS, 2007), também é outro exemplo de texto cujo mote são as alterações diacrônicas do léxico (o texto apresenta palavras e expressões cristalizadas que eram utilizadas - algumas ainda o são -, como o título explicita, antigamente e que foram sendo deixadas de lado pelos usuários da língua; o texto também faz menção às alterações ortográficas, como phtysica, por tísica, o mesmo que tuberculose pulmonar; asthma, por asma). Da música popular, também se extrai um exemplo de variação diacrônica: a letra da canção "No tempo de Don-Don" ${ }^{2}$, de Nei Lopes, arrola uma lista de palavras que foram sendo substituídas ao longo do tempo, caindo em desuso (como nos versos "Propaganda era

2 In https://www.letras.mus.br/nei-lopes/tempo-de-don-don/ Acesso em 10.Jul.2020. 
reclame, ambulância era dona assistência,/ Mancada era um baita vexame, e pornografia era só saliência/ Sutiã chamava porta-seio (sic), revista pequena gibi").

As variedades geográficas ou diatópicas podem ser abordadas por meio de vídeos que demonstrem não só as diferenças entre o português do Brasil e o de outros países lusófonos (como Portugal), mas também as variedades internas do português brasileiro (os seus diferentes falares). Com o recurso da internet, é possível ter acesso a vídeos, como o do anúncio publicitário da Caixa Geral de Depósitos, instituição bancária portuguesa, protagonizado por Luís Felipe Scolari, que já foi técnico das seleções brasileira e portuguesa. Na peça publicitária ${ }^{3}$ o técnico destaca a necessidade de o imigrante brasileiro aprender a se adaptar à variedade europeia da língua portuguesa, principalmente em relação ao léxico (hospedeira por aeromoça, atacador por cadarço, talho por açougue, comboio por trem, claque por torcida, matraquilhos por pebolim). Textos conhecidos de Jorge Amado (1992), como “Bahia, 1964. Língua Portuguesa”, e de Ruy Castro (1978), "Como ser brasileiro em Lisboa sem dar muito na vista", também tratam dessas diferenças geográficas. A fim de abordar a existência de diversos falares no português brasileiro, o artigo "Sotaques do Brasil:

3 In https://www.youtube.com/watch?v=axlGvp7KHdo Acesso em 9.Jul.2020. 
como a geografia afeta o nosso modo de falar de norte a sul" (MESTIERI, 2018), da Revista da Babbel, apresenta as dificuldades que os estrangeiros têm para compreender as diferenças decorrentes dos diversos falares (a variação diatópica interna do Brasil), muitas delas exemplos de gírias. Há ainda uma série de reportagens produzida pelo Jornal Hoje (TV Globo), que aborda a variação geográfica, a partir da elaboração do Atlas Linguístico do Brasil, tratando de aspectos lexicais e fonológicos ${ }^{4}$.

Ao abordar a variação geográfica, o professor pode tratar das diferentes pronúncias dos fonemas praticadas pelos falantes do português do Brasil. Dessa forma, ele permite ao aluno compreender que a pronúncia das vogais, por exemplo, pode variar, mas elas deverão ser escritas da mesma maneira no país todo, uma vez que a escrita ortográfica é única, enquanto a forma de pronunciá-las não, em decorrência da diversidade linguística.

Ao tratar das variações socioculturais ou diastráticas, o professor poderá fazer uso de textos jornalísticos, como por exemplo, editoriais, para demonstrar as características da linguagem formal, e textos literários, como as crônicas, para apresentar exemplos da linguagem coloquial, uma vez

4 In http://g1.globo.com/jornal-hoje/noticia/2014/08/sotaques-do-brasil-desvendadiferentes-formas-de-falar-do-brasileiro.html Acesso em 9.Jul.2020. 
que nesse gênero ela é empregada como uma estratégia de aproximação com o leitor. Letras de música também podem ser analisadas de forma a verificar que nível de linguagem é predominante. A canção "Rosa", de Pixinguinha e Otávio de Souza, é um bom exemplo do predomínio do nível formal (como o emprego de um vocabulário erudito e da ordem indireta, predominância da $2^{a}$ pessoa do singular, emprego do verbo haver nas locuções verbais hei de amar-te, hei de envolver-te). A gíria, como uma forma de caracterização linguística, também pode ser abordada em histórias em quadrinhos, letras de música, contos e crônicas.

Em relação às modalidades oral e escrita, é possível estimular a produção de textos orais e escritos a partir de um fato do cotidiano, solicitando ao aluno que o apresente oralmente à sua turma e depois que escreva uma notícia sobre ele. Ele também pode entrevistar alguém e depois transcrever essa entrevista. Dessa forma, ele terá que identificar as características de cada modalidade e empregálas adequadamente em suas produções textuais. A função das aulas de Língua Portuguesa é proporcionar situações em que o aluno venha a se expressar de forma oral e escrita, desenvolvendo suas habilidades comunicativas e aprendendo a respeitar as regras de cada modalidade.

5 In https://www.letras.mus.br/pixinguinha/30843/ Acesso em 9.Jul.2020. 
Ao incluir a variação linguística no ensino, a aquisição da norma-padrão não pode ser esquecida. Apesar do consenso de que o ensino de Língua Portuguesa não deve se resumir a ela (como vimos, existem outras variedades e todas deveriam gozar do mesmo respeito e valorização), o aluno vai à escola também para aprendê-la, porque isso lhe proporcionará os meios de interagir em condições de igualdade com os outros falantes, podendo exercer plenamente sua cidadania. Portanto, o professor deve proporcionar o contato com a diversidade linguística por meio de uma variada gama de textos, sem se esquecer daqueles em que a norma-padrão poderá ser abordada.

\section{CONSIDERAÇÕES FINAIS}

Abordar a variação linguística é mais que necessário, é fundamental. A análise dos dois documentos oficiais mais importantes do ensino de Língua Portuguesa (os PCN e a BNCC) só reforça essa realidade. Esses dois documentos são uma fonte histórica de como vêm se transformando, ao longo do tempo, as concepções linguísticas, incorporandose ao ensino noções como as de língua como entidade heterogênea e dinâmica, como um conjunto de variedades; a de necessidade de abordar a variação linguística (em relação às diferenças diacrônicas, diatópicas, diastráticas); a de incorporação do trabalho com a modalidade oral, não 
somente com a escrita; a de ressignificação do conceito de erro, preferindo-se a noção de adequação linguística; a de substituição do preconceito linguístico pela aceitação e pela valorização das diferentes variedades linguísticas.

A BNCC representa uma continuidade da abordagem linguístico-didática que vem sendo empreendida desde a formulação dos PCN, mantendo sua perspectiva enunciativodiscursiva. No entanto, na BNCC, foi possível identificar um traço um pouco mais saliente: o maior destaque dado à aquisição da norma-padrão.

A preocupação em implementar um ensino que valorize a variação linguística, o que se comprova por meio de documentos oficiais que norteiam a formulação de currículos escolares e de livros didáticos, como os PCN e a BNCC, é um indício de que esse tipo de abordagem ainda é um objetivo a ser alcançado, mas não pode deixar de ser considerado um sinal positivo de que as contribuições dos estudos linguísticos têm sido incorporadas com maior frequência ao ensino de Língua Portuguesa.

\section{REFERÊNCIAS}

AMADO, Jorge (1992). "Bahia, 1964. Língua portuguesa". In:

Navegação de cabotagem: apontamentos para um livro que jamais escreverei. Rio de Janeiro: Record. p.126-128.

BECHARA, Evanildo (2006). Ensino da gramática: opressão?, liberdade? São Paulo: Ática. 
BRASIL (1998). Secretaria de Educação Fundamental. Parâmetros Curriculares Nacionais: terceiro e quarto ciclos do ensino fundamental: língua portuguesa. Brasília, DF: MEC/SEF. (2018). Ministério da Educação. Base Nacional Comum Curricular. Brasília, DF: MEC. In http://basenacionalcomum.mec.gov.br/images/ BNCC_EI_EF_110518_versaofinal_site.pdf Acesso em 09.Jul.2020.

CASTRO, Ruy (1978). "Como ser brasileiro em Lisboa sem dar muito na vista". Viaje Bem, Revista de bordo da VASP, (8).

CUNHA, Celso (1994). Língua portuguesa e realidade brasileira. 10.ed. Rio de Janeiro: Tempo Brasileiro.

FÁVERO, Leonor Lopes; ANDRADE, Maria Lúcia C. V. O.; AQUINO, Zilda G. O. (2002). Oralidade e escrita: perspectivas para o ensino de língua materna. 3.ed. São Paulo: Cortez.

FARACO, Carlos Alberto; ZILLES, Ana Maria (2017). Para conhecer norma linguística. São Paulo: Contexto.

HOUAISS, Antônio (1992). O português no Brasil. 3.ed. Rio de Janeiro: Revan.

ILARI, Rodolfo; BASSO, Renato (2006). O português da gente: a língua que estudamos a língua que falamos. São Paulo: Contexto.

MACHADO, Ana Maria (2007). Bisa Bia, Bisa Bel. 3.ed. Rio de Janeiro: Salamandra.

MATEUS, Maria Helena Mira; CARDEIRA, Esperança (2007). Norma e variação. Lisboa: Caminho.

MESTIERI, Gabriel (2018). "Sotaques do Brasil: como a geografia afeta o nosso modo de falar de norte a sul". Revista da Babbel. 3 de janeiro. In https://pt.babbel.com/pt/magazine/os-sotaques-do-brasil-comofalamos-de-norte-a-sul?bsc=gg_ytb_pormag_bv71\&btp=default Acesso em 9.Jul.2020.

PRETI, Dino (1994). Sociolinguística: Os níveis da fala: Um estudo sociolinguístico do diálogo na literatura brasileira. 7.ed. São Paulo: Editora da Universidade de São Paulo. 
SANTOS, Joaquim Ferreira dos (Org.) (2007). As cem melhores crônicas brasileiras. Rio de Janeiro: Objetiva.

TERRA, Ernani (2018). Linguagem, língua e fala. 3.ed. São Paulo: Saraiva.

Claudia Moura da Rocha é Doutora em Língua Portuguesa pela Universidade do Estado do Rio de Janeiro (UERJ), onde leciona como professora adjunta do Departamento de Língua Portuguesa, Literatura Portuguesa e Filologia. Atua na Graduação e na Pós-graduação lato sensu. É professora da rede municipal do Rio de Janeiro, já tendo lecionado no Ensino Fundamental (1o segmento) e Ensino Médio. É membro do grupo SELEPROT.

E-mail: claudiamoura@infolink.com.br. 